\title{
BIOSTATISTIC, LEGISLATIV AND ETHICAL PROBLEMS OF COMPARATIVE CLINICAL STUDIES. I. GENERIC AND BIOSIMILAR DRUGS CASE
}

\author{
RALUCA GAVRILA $\breve{1}^{1}$, MONICA ISAILA $\breve{~}^{2,4}$, CONSTANTIN MIRCIOIU ${ }^{1,4}$, FLORENTINA \\ GHERGHICEANU $^{1}$, ISABEL GHIȚA ${ }^{1}$, IRINA PRASACU ${ }^{1} *$, ION MIRCIOIU ${ }^{3}$ \\ I "Carol Davila" University of Medicine and Pharmacy, Bucharest, Romania \\ ${ }^{2}$ Ministry of Health, Juridical Department, Bucharest, Romania \\ ${ }^{3}$ Medicient SRL, Bucharest, Romania \\ ${ }^{4}$ National Commission of Bioethics of Drugs and Medical Devices, Bucharest, Romania
}

*corresponding author: irinaprasacu@yahoo.com

\begin{abstract}
This paper presents an ethical approach of the clinical studies, biostatistical and legislative aspects for testing generics and biosimilars and the valuation of the obtained results in clinical practice and health politics. Both generics and biosimilars are considered as alternative treatments contributing essentially to ensure the human right to health, cost and life savings for large populations. In case of generics, interchangeability is accepted practically in all countries. An ethical direction more to be considered in the future is the biowaiver of the in vivo bioequivalence clinical trials based on in vitro dissolution studies and knowledge concerning the in vitro - in vivo correlations. Population and individual bioequivalence as alternative to average bioequivalence are considered non-ethical in the context of risk-benefit balance in bioequivalence studies concerning generics, but could be further considered in case of biosimilars. This paper makes a comparative analysis of the regulations in different countries concerning prescribability and interchangeability of biosimilars. The conclusion of the authors is that prescribability is perfect by applicable in both cases of generics and biosimilar drugs. Interchangeability is considered applicable in case of generics and desired in case of biosimilars but mainly after establishing the appropriate biostatistical methods for the design of the corresponding bioequivalence clinical trials and analysis of results.
\end{abstract}

\section{Rezumat}

Lucrarea prezintă o abordare etică a unor aspecte biostatistice și etice a studiilor clinice care evaluează medicamentele generice și biosimilare precum și valorificarea rezultatelor în practica clinică și în politica de sănătate. Atât genericele cât și biosimilarele sunt considerate ca tratamente alternative ce contribuie la un drept esențial al omului - dreptul la sănătate. În cazul genericelor, în acest moment interschimbabilitatea este acceptată practic în toate țările. O direcție etică ce se impune a fi dezvoltată mai mult in viitor este " biowaiver", exceptarea de la studii clinice pe baza rezultatelor studiilor de dizolvare și a corelarilor in vitro - in vivo. Bioechivalența individuală și cea populațională ca alternative la bioechivalența medie sunt considerate ne-etice în contextul balanței risc - beneficiu în studiile de bioechivalență privitoare la generice dar pot fi reevaluate şi considerate în cazul biosimilaritații. Lucrarea face o analiză comparativă a reglementarilor din diferite țări privind prescribabilitatea şi interschimbabilitatea biosimilarelor. Concluzia autorilor este că prescribabilitatea este perfect aplicată practic in toate țările, atât pentru generice cât și pentru biosimilare. Interschimbabilitatea este aplicabilă în cazul genericelor. În cazul biosimilarelor devine aplicabilă după stabilirea unor metode biostatistice corespunzătoare privind desfășurarea studiilor de bioechivalență și analiza rezultatelor acestora.

Keywords: bioequivalence criteria, biowaiver, biosimilars interchangeability, health human wright

\section{Introduction}

Research for alternative methods, drugs and treatments are maybe in the main stream of the evolution in medical sciences in the last fifty years and will remain so in the future, this direction being imposed essentially by governments, which are concerned to reduce the burden carry of expensive health costs and civil society looking for the decrease of medical research risks. Alternative research methods to laboratory animals, generic alternative drugs, biosimilars and, in a more general way, alternative treatment methods became a central domain in research and clinical practice.

"Generic" alternative bioequivalent drugs contain the same active substance, attain similar rates and extent of absorption with a reference drug and are tested for the clinical effect. These rules are well defined and interchangeability is clearly regulated and harmonized between countries.

Rules for proving by statistical methods that a generic drug reaches similar plasma levels with the reference drug are very clear defined and the axiom 
FARMACIA, 2018, Vol. 66, 6

that similar pharmacokinetics imply similar effects is accepted by all regulatory bodies [13]. Retrospective statistics on thousands of studies presented for approval to FDA showed that this is really the case in practice, bioequivalence implying therapeutic equivalence [7].

Some clinicians fear about the possibility of nontherapeutic equivalence in case of highly variable drugs and those with narrow therapeutic index. For example in case of antiepileptic drugs, there were published more than 90 papers in this direction warning about the risk of non-therapeutic equivalence in spite of bioequivalence [2] but they never presented clinical data to sustain their affirmation. As was stated by the main scientific counsellor in problems of biopharmacy of FDA, Leslie Benet, "no prospective study has ever found that an FDA approved generic product does not show the same clinical efficacy and safety as the innovator product, even when special populations (e.g., elderly, women, severely sick patients) are studied" [3]. On the contrary, biosimilarity of drugs of biological origin is more difficult to prove and their interchangeability is much disputed and differently regulated from country to country, partly due to the difficulties in proving their bioequivalence.

In the most general sense, rules for selecting the most appropriate treatment or change of a treatment with an equivalent one represent a complex and vast domain, implying a serious statistical analysis, a large amount of uncertainty and many disputes concerning accepted methodologies. In particular, interchangeability in the same time imposes questions regarding the clinical efficacy, safety and social ethics. The present paper intends to review the main biostatistical and legislative criteria considering the health politics and ethical principles regarding the patients.

\section{Biostatistical aspects}

\section{In vivo bioequivalence}

Drugs containing the same active substance, having the same pharmaceutical form and achieving similar areas under plasma concentration curves are called bioequivalent.

A quantitative rigorous definition concerning bioequivalence of a tested drug $T$ with a reference drug $R$ is based on the $90 \%$ confidence interval for ratio of means $\mu$ of the main pharmacokinetic parameters - area under curve $(A U C)$ and maximum concentrations Cmax, compared to $0.8-1.25$ interval [29],

$$
P\left(0.8<\frac{\mu_{T}^{A U C_{0-\infty}}}{\mu_{R}^{A C_{0 . \infty}}}<1.25\right) \geq 0.9 \quad P\left(0.8<\frac{\mu_{T}^{C_{\text {max }}}}{\mu_{R}^{\operatorname{mox}}}<1.25\right) \geq 0.9
$$

The statistical problem is that the confidence interval is built around the experimental found difference between means, based on the supposition of a normal distribution of the pharmacokinetic parameters $-z$ and uses estimations $\hat{\sigma}_{d}$ from pharmacokinetic results of the intra subject's variance of parameters:

$C I_{0,90}=\left((\bar{T}-\bar{R})-z_{\left(1-\alpha / 2, n_{1}+n_{2}-2\right)} \hat{\sigma}_{d} \sqrt{\frac{1}{n_{1}}+\frac{1}{n_{2}}},(\bar{T}-\bar{R})+z_{\left(1-\alpha / 2, n_{1}+n_{2}-2\right)} \hat{\sigma}_{d} \sqrt{\frac{1}{n_{1}}+\frac{1}{n_{2}}}\right)$

where $n_{1}$ and $n_{2}$ represent the number of subjects in the $R T$ and $T R$ sequences in case of cross-over studies. In practice there is usually used the lognormal distribution, but the difference is not significant in terms of the actual difficulties concerning the CI construction. The real problem is the estimation of variance of parameters.

In standard cross-over, two periods two sequences studies, the obtained variance is a pool of reference and tested drug variances. From the theoretical point of view, it is expected that the variability of a generic drug to be lower than that of the reference for several reasons: the generic drug is developed twenty years later than the reference drug, after a progress of excipients quality, manufacturing technologies and information concerning variability causes of the formulations containing the active substance.

These situations were reported by many authors which proposed an enlargement of acceptance intervals for bioequivalence, by scaling the limits with the reference variability.

In the absence of this scalation, it may happen that a bioequivalence study fails due to the high variability and outliers of the reference drug [28, 34].

In order to verify that the interval hypotheses that $C I_{0.90}$ is included in the acceptance limits there is tested the following hypothesis:

\section{$H_{0}$ : Bioinequivalence versus $H_{a}$ : Bioequivalence,}

which are further analysed using Schuirmann's two one-sided tests procedure [29]. The $H_{0}$ hypothesis refers to the ethical reasons of inequivalence, that is to minimise the patients' risk.

Generic automatic substitution is allowed in all cases and, at least in the US, is an attribute of pharmacists. Following the evolution of pharmaceutical technology, mainly by embedding active substances in micro and nanoparticles, "the same pharmaceutical formulation" becomes sometimes a problem of methodology for proving bioequivalence which is consequently more or less disputable. For this reason, the bioequivalent drugs which have no problem in proving bioequivalence are freely interchangeable [19]. There are challenges in establishing appropriate rules for determining bioequivalence for drugs 
FARMACIA, 2018, Vol. 66, 6

containing the active substance embedded in micro and nanosystems, called "Non - Biological Complex - Drugs" [4], drugs with complex pharmacokinetics (i.e. enterohepatic circulation) [33] or drugs with active metabolites [20], drugs administered intravaginal [21], topical drugs [31].

In vitro bioequivalence

In vitro bioequivalence is assigned if two formulations containing the same active substance achieve the same release kinetics. The guidelines, for reasons of simplification and standardization, speak about dissolution instead of release kinetics: "dissolution curves" or "dissolution profiles".

For defining similarity of the release profiles there were proposed different "dissolution metrics", based on differences (delta type) or ratio (ro type) of the matching values $\left(R_{i}, T_{i}\right)$ of active substance released percent at different measuring times:

$$
\delta=\frac{2 \sum\left|R_{i}-T_{i}\right|}{\sum\left(R_{i}+T_{i}\right)} \quad \rho^{\prime \prime}=\frac{\sum\left(R_{i}+T_{i}\right) \max \left(\frac{R_{i}}{T_{i}}, \frac{T_{i}}{R_{i}}\right)}{\sum\left(R_{i}+T_{i}\right)}
$$

From the large family of metrics, official is only the f2 metric:

$$
f_{2}=50 \log \frac{100}{\sqrt{1+\frac{\sum_{i=1}^{n}\left(\mu_{r i}-\mu_{t i}\right)^{2}}{n}}}
$$

If $\mathrm{f} 2<50$ dissolution curves are dissimilar, if $50<$ f2 $<100$ the dissolution profiles are similar. This similarity is most relevant in case of extended release formulations allowing the selection between different formulations in order to assure a controlled release [26].

In vitro - in vivo correlations

For extended release formulations, FDA guidelines specifiy five correlation levels, which offer the ability to predict the pharmacokinetics of the active substance after oral administration. From the beginning of in vitro - in vivo correlations (IVIVC) up today, some fair validated linear correlations were obtained. In the same time, in other cases, there were obtained poor linear correlation or uncorrelated data [23].

Although most of the work on the IVIVC is based on linear relationships, both the USP and the FDA state that non-linear models are acceptable to describe the in vitro-in vivo relationships [11].

The active substance fraction absorbed is calculated, for example, using the Wagner-Nelson equation [35]:

$$
F R A\left(t_{i}\right)=\frac{c\left(t_{i}\right)+\int_{0}^{t} k_{e} c d t}{\int_{0}^{\infty} k_{e} c d t}=\frac{c\left(t_{i}\right)+k_{e} A U C_{0-t_{i}}}{k_{e} A U C_{0-\infty}}
$$

where: $F R A\left(t_{i}\right)=$ fraction of the drug absorbed at time $t_{i}$, $c\left(t_{i}\right)=$ plasma concentration of the drug at time $t_{i}$, $k_{e}=$ elimination rate constant for the drug,
$A U C_{0-t_{i}}=$ area under the concentration-time curve of the drug from time 0 to time $t_{i}$, $A U C_{0-\infty}=$ area under the concentration-time curve of the drug from time 0 to infinity.

This relation is in fact the mass balance method. It is applicable in cases when the release the kinetics from the pharmaceutical formulation is slower than the absorption, and the rate of the appearance of the active substance in blood equals the release rate. If in vitro dissolution tests are "biorelevant", i.e. the conditions and performance are related with in vivo ones, it is generated an alternative method for predicting in vivo absorption.

Biowaiver of the in vivo bioequivalence

In vitro comparative studies as alternative to the in vivo clinical trials are less considered due to the pressure of the public opinion. In the last years biowaiver of in vivo experiments in proving the bioequivalence of generic drugs with reference brand drugs is a singular example of both the desire to reduce human risks in clinical trials and to reduce expenses $[12,26]$.

Biowaiver is possible based on Biopharmaceutics Classification System [1] and Biopharmaceutics Drug Disposition Classification System [6] for a restricted number of drugs, mainly those with slow release from the pharmaceutical formulations and rapid absorption. The main statistical instrument in deciding bioequivalence is the correlation of in vitro dissolution determined experimentally and the in vivo dissolution estimated from the deconvolution of pharmacokinetics, so called IVIVC [22, 23, 27].

Biosimilars

Biological drugs contain active substances from a biological source, such as living cells or organisms. Most biological medicines in current clinical use contain proteins. Their molecular weight is much higher than that of the synthetic drugs and their structure is less defined so that the criterion "the same structure" used for generics become "similar structure".

For the assessment of similarity between biologics, FDA [17] established the following criteria: the reproducibility of the manufacturing process; bioequivalence; comparative immunogenicity.

Additionally there are required similar mechanisms of action, structural similarity and the existence of a valid PK/PD model. Surely, these criteria are rather desiderates since in practice all mechanisms are in fact a mixture of some results and more hypotheses. The rules applied for assessing bioequivalence of generics are only in few cases possible for testing bioequivalence of biosimilars [10]. For approval of biosimilars, EMA elaborated a guideline with general principles, in 2003 [9], and it was followed by other documents related to specific products. It 
is to note that in fact specific guidelines were rather reviews of published data concerning the products and remained uncleared concerning specific scientific requirements.

EU approved the first biosimilar medicine in 2006. The evidences acquired over 10 years of clinical experience show that biosimilars approved by EMA can be used as safely and effectively in all their approved indications as other biological medicines.

\section{Drug prescribability and switchability}

When a new medicine is administered to a patient, there are two situations. First is the case when patient is "naive" i.e. is the first time when he receives a drug from a list of alternative formulations containing the same active substance. The physician has to make a choice in prescribing one or another formulation from a list of drugs including the brand name and several generics which fulfil some "prescribability" criteria.

Another case is that when the patient is under treatment with a drug and wants to change it with a bioequivalent one. We discuss in this case about drug switchability, or more generally, interchangeability.

\section{Population/individual bioequivalence}

Some statisticians consider that the average bioequivalence of biologic drugs can guarantee neither drug prescribability, nor drug switchability. It was suggested that the assessment of biosimilarity should take into consideration both prescribability and switchability using specific criteria.

Mathematically, the new proposed criteria replaced a metric based on rhombic norm (sum of the modules of the components) with metrics based on spherical norm (square root of the sum of squares of the components) or, in statistical terms, replacing [30] the probability criterion $P\left(\left|X_{T}-X_{R}\right|<r\right)$, by a momentum based criterion $E\left(X_{T}-\left.X_{R}\right|^{2}\right)<r$, where $\mathrm{E}$ is the "expectation operator" calculating the mean of random variables.

\section{Population bioequivalence criterion}

Extensive discussions generated by FDA biostatisticians looked to impose the population bioequivalence (PBE) and individual bioequivalence (IBE) criteria for testing prescribabilty and switchability. Population bioequivalence criterion was defined as:

$$
P B E=\frac{\left(\mu_{T}-\mu_{R}\right)^{2}+\left(\sigma_{T T}^{2}-\sigma_{T R}^{2}\right)}{\max \left(\sigma_{T R}^{2}, \sigma_{T 0}^{2}\right)} \leq \theta_{p},
$$

where $\mu_{\mathrm{T}}$ and $\mu_{\mathrm{R}}$ are the means of the test and reference drug products, respectively, $\sigma_{T T}^{2}$ and $\sigma_{T R}^{2}$ are the total variances, $\sigma_{T 0}^{2}$ is a constant, and $\theta_{P}$ is the acceptance limit for PBE.

Individual bioequivalence criterion (IBC) for drug switchability

Similarly, for assuring switchability, it was recommended the following aggregated, scaled, moment-based, individual bioequivalence, onesided criterion:

$$
I B C=\frac{\left(\mu_{T}-\mu_{R}\right)^{2}+\sigma_{D}^{2}+\left(\sigma_{W T}^{2}-\sigma_{W R}^{2}\right)}{\max \left(\sigma_{W R}^{2}, \sigma_{W 0}^{2}\right)} \leq \theta_{p}
$$

where $\sigma_{W T}^{2}$ and $\sigma_{W R}^{2}$ are the within-subject variances of the test and reference drug products, respectively, $\sigma_{D}^{2}$ is the variance component due to subject-by-formulation interaction, $\sigma^{2}{ }_{0 \mathrm{~W}}$ is a regulatory constant, and $\theta_{\mathrm{I}}$ is the bioequivalence limit for IBE. It was suggested that PBE can be applicable to new formulations or new dosage forms, while IBE is to be applied for generic drugs. Debates were finally closed due to the opposition of both industry and universitary clinicians. The main argument was that considering both differences and variances of a tested drug $\mathrm{T}$ and a reference one $\mathrm{R}$ there are needed designs like (1) Balaam (TT, RR, $\mathrm{RT}, \mathrm{TR})$; or two-sequence, three-periods $(2 \times 3)$ dual design - (TRT, RTR), or (3) two-sequence, four-periods (2 x 4) design - (TRTR, RTRT), meaning long time and expensive experiments. So that average $\mathrm{BE}$ remained the standard method to assure the efficacy and safety of generic products. But, in context of biosimilarity, following the much higher complexity of the biologic drugs, it is sure that aggregated criteria taking in the same time in consideration the differences and the variances of pharmacokinetic parameter have to be re-evaluated.

\section{Prescribability and interchangeability of biosimilar drugs, legislative aspects}

Fundamental differences between biosimilars and generics

In comparison with generics, biosimilars have to be "sufficiently similar" to a reference drug. This means in the same time bioequivalence and proving the safety, efficacy and immunogenicity by clinical trials, correlated with previous scientific information to allow interchangeability of the two products. But since this is very difficult to obtain in practice, the biosimilars have to be evaluated also for long time effects and the rules for admitting interchangeability are still oscillating.

In the US, in order to receive the approval for a biosimilar, two phases are required. First a similarity between the biosimilar the drug and the reference product must be demonstrated. Secondly the producer of the biosimilar drug must provide all the safety data. From 2014, the FDA has begun to develop a series of regulations and guidelines 
FARMACIA, 2018, Vol. 66, 6

regarding the approval of biosimilars. In 2017, FDA published "Considerations in Demonstrating Interchangeability With a Reference Product Guidance for Industry" [39]. The "Purple Book" lists biological products, including all biosimilar and interchangeable biological products, licensed by FDA under the Public Health Service Act (the PHS Act) [40].

The general opinion in the USA is divided, as some states (such as Texas and Arizona) reject these proposals. However, over the years, there have been other regulations regarding biosimilar drugs in the USA. One example is the Biologics Prize Competitions and Innovation (BPCI) Act, which was passed in 2009. This law is in direct relation with the Public Health Service Act (PHS Act). The BPCI Act was used to summarize the approval process for biological drugs, regarded as biosimilar drugs, or interchangeable drugs, with a reference product, approved by the FDA. "The terms interchangeable and interchangeability mean that: (1) the biological product is biosimilar to the reference product; (2) the biological product can be expected to produce the same clinical result as the reference product in any given patient; (3) for a product administered more than once, the risks of safety and reduced efficacy of alternating and switching are not greater than with the use of the reference product without alternating or switching" [5]. We must emphasize not to confuse biosimilarity and interchangeability. While in order to be interchangeable a product must be biosimilar, but being a biosimilar drug does not automatically mean it is an interchangeable drug.

Regarding the European Union, this was the first to publish a number of regulations for the process for biosimilars approval. The EU clearly divides the approval of a biosimilar and its condition as an interchangeable drug. Moreover, EMA is not supposed to designate a biosimilar drug as an interchangeable one. This decision must be taken by the Member States of the EU. Biosimilar approval is a centralized procedure, based on the regulatory requirements of the EU. The interchangeable status of a product must be established at a national level.

That is to say, EU member states hold different stances regarding biosimilar interchangeability. Each country has the authority to determine if such substitutions are permitted. For example, some countries (Austria and Portugal) do not even have regulations regarding the biosimilar drugs. Germany and Italy strictly interdict automatic substitution, while Ireland, Spain and Norway have laws that specifically prohibit the substitution of drugs.

The substitution of biosimilars was first allowed in France. Article 47 of the Law of 23 December 2013 states that the substitution of biosimilars is only permitted on the condition that a new treatment is started, the biosimilar belongs to the same pharmacological group as the prescribed product, and that the doctor has not explicitly prohibited, in writing, the substitution of the prescribed drug [41]. Regarding Finland, the Finish Medicines Agency (FIMEA) outlined in 2015 their stance on interchangeability of biosimilars. Their conclusion was that the biosimilars are only interchangeable when strictly supervised by a healthcare professional [18].

In Netherlands, the regulatory agencies state that interchangeability is conditioned by the informed consent of the patient and the clinical monitoring.

Germany [42] allows the use of biosimilars exactly the same as their reference products, as long as the bioequivalence has been demonstrated.

The Health Products Regulatory Authority (HPRA), the regulatory agency in Ireland, states that a communication between the prescribing doctor, the patient and the pharmacist is necessary, as the doctor must be involved in the decision process of using the biosimilar and the reference product [43].

Regarding Spain, the substitution of biological drugs is not allowed, thus disregarding whether or not the drug is a biosimilar. This decision was made through the Ministerial Order SCO/2874/2007, of 28 September and a note released by the Spanish Agency of Medicine and Medicinal Devices (AEMPS) on 24/04/2009 on ,Medicinal products that should not be substituted by another medicinal product with the same active substance without express permission from the prescribing doctor". During recent years, the Law on guarantees and rational use of medicinal products stated that ,in the case of biosimilar medicinal products, the current standards contained in the specific regulation pertaining to substitution and interchangeability will be respected" (Article 90.5 of the revised text in Royal Legislative decree 1/2015).

Canada has replaced the term interchangeability with the term substitutability. This term describes two products that can be used instead of one another. The opinion of Health Canada on the replacement of biological products is as follows: „Health Canada does not support the automatic substitution of a subsequent-entry biologic for its reference biologic drug. Health Canada therefore recommends that physicians make only well-informed decisions regarding therapeutic interchange" [36]. In Japan, the regulations of biosimilar drugs also state that these products have to bear nonproprietary names. Moreover, the convention is that a biosimilar drug's name must include the name of the reference product, to which the suffix biosimilar must be added, alongside the number which indicated the order in which the biosimilar received approval 
FARMACIA, 2018, Vol. 66, 6

in Japan. A definition of interchangeability is not given by the Japanese regulatory agency. Moreover, the pharmacist does not have the authority to substitute a biosimilar drug. That is to say, the decision must only be made by a physician [37].

Romania applies all rules established by EMA and accepted at European level. A national particular regulation concerning interchangeability of biosimilars is presently missing.

According to the Government Decision no. 155 of March 30, 2017, approving the national health programs for the years 2017 and 2018, Art. 11, provides that the pharmacists have the obligations not to substitute a biological product with its biosimilar, in the absence of a physician recommendation [16].

In 2014 the Local American Working Group including Abbvie, Amgen, AstraZeneca, Bristol-Myers Squibb, Eli Lilly, Glaxo Smith Kline, Johnson \& Johnson, Merck Sharp \& Dohme, Novartis, Pfizer, and Roche performed an information concerning aspects of utilization of biological drugs [8]. The main conclusion of the document is that not only costs have to be considered in health politics.

The problem is that this information, correct in form, is incorrect in the socio-politic context. There should be a balance between the risks associated with the change from a drug to another and the population's access to medication [32]. Cost is not the single criterion, but lower costs assure a chance to treat much more patients.

Retrospectively it was appreciated that application of the mentioned law permitted an easier access to life savings generic drugs. For example, in the period 2003 - 2012, generic substitution generated more than $\$ 1.2$ trillion in savings to the health care system in USA and contributed to the well-being of innumerable lives [15].

Generic and biosimilar medicines are a marketbased solution that increases competition and lowers costs for patients. In the last decade, the US health care system has saved $\$ 1.67$ trillion due to the availability of low-cost generics [44].

\section{Ethical aspects}

\section{Costs and life saving}

One problem of governments is to reduce the expenses associated to continuously increasing of costs of drugs and aging.

In 2015 generic drugs accounted in US for $88 \%$ of all prescriptions filled and the predictions for generics state that will represent some $91 \%-92 \%$ of prescriptions by 2020 [38]. A similar evolution appeared in UK. In Romania the sales [14] of generic drugs is around $23 \%$ (Figure 1).

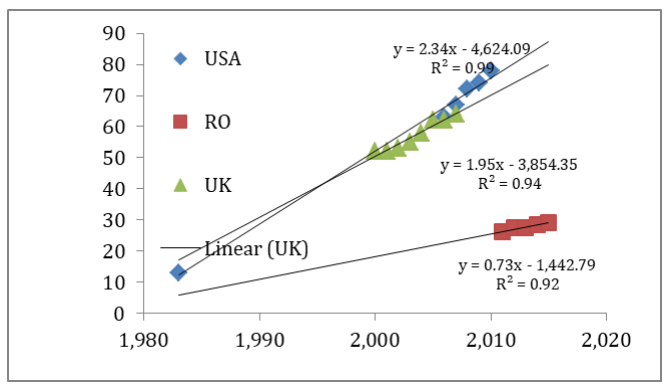

Figure 1.

The evolution of sales of generic drugs in USA, UK and Romania between 1980 and 2020

Data concerning number of prescriptions, sales in volume and sales in currency are not directly comparable, but the slopes for evolutions are clearly higher (2.34 and 1.95 compared to 0.73$)$ in USA and UK.

Concerning the biosimilar market the situation will probably be in future comparable to the generic market. A research performed by specialists from RAND Health, sponsored by Sandoz, estimated that as a consequence of regulatory frame improvement and in conditions of a competitive market "the cost savings potential of biosimilars to be $\$ 54$ billion over ten years using recent baseline data and transparent assumptions, with a lower- to upperbound range of $\$ 25$ billion to $\$ 150$ billion" [25].
From the ethical point of view, the most important aspect remains to assure the fundamental human right of access to health services.

Involving healthy volunteers in bioequivalence studies

A possible ethical question in bioequivalence studies is the inclusion of healthy volunteers, since they have not a therapeutic benefit from participating in such studies. The first justification of including this category is the benefit of future patients which is the fundament of all clinical studies. Another reason is that the composition is identical in the two products and there are not reasons to fear on new adverse reactions.

Ignored biopharmaceutical component of absorption variability

The variability of release kinetics can imply the risk of outliers. For this reason, in vitro bioequivalence 
testing has to be performed before starting the in vivo experiments. IVCVC correlations come to strengthen the conviction that the risk of unexpected reactions will appear further in clinical practice.

A completely ignored problem in clinical trials is the variability of the in vivo release kinetics of active substances from drugs. Almost all drugs have a low solubility in water and are administered as salts. Salts are released in the gastric content very easy and rapid, from where is drawn the false conclusion that of a good bioavailability. In fact, the transfer from acid $\mathrm{pH}$ to neutral or week alkaline in intestine leads to a drastic decrease of solubility and precipitation. Sometimes the precipitation is not immediate and it is preceded by formation of a supersaturated solution. Whatever the case, the availability for absorption of the active component in intestine is highly variable. So, in the frame of studying the efficacy and safety profile of a drug, it is necessary to add estimations of intra and intervariability of the active substance pharmacokinetics induced by the variability in dissolution kinetics. Unfortunately, this type of information is missing in practically all performed clinical trials.

Risks of patients involved in testing efficacy and safety of biosimilars

It is sometimes asserted that a patient needs best treatment available and the administration of a biosimilar is unethical since "a known and proven treatment for the respective indication is already available" according to Helsinki Declaration.

If these requirements were to be applied ad literam in all cases, much of the clinical research performed in course of the development of a biological drug would be no more acceptable. Anyway, the risks implied by switching to biosimilars is lower than the risks from the lack of access to the reference drug following the lack of financial support.

Advocating further, these studies offer a chance to obtain more therapeutic options for patient. In such a perspective, the research is no more redundant.

\section{Conclusions}

Generics and biosimilars are appropriate alternative treatments. Their prescribability and interchangeability have to be considered in economic aspects and in connection with the fundamental human right to health.

Existing bioequivalence criteria correlated with the in vitro dissolution tests, which have to be added to bioequivalence studies, can assure both prescribability and interchangeability of generic drugs.

Prescribability and interchangeability of biosimilars are differently regulated or even not regulated, from one country to another. More efforts toward scientific bases of regulations and harmonization, for the design of bioequivalence clinical trials and analysis of results have to be made for the assurance of interchangeability. Momentum based metrics, which take into consideration aggregated differences and variabilities of pharmacokinetic parameters, allow the re-evaluated of the criteria for population and individual bioequivalence assessment. The risks of patients in biosimilarity clinical trials have to be evaluated scientifically and specifically for different types of biologics.

\section{References}

1. Amidon GL, Lennernäs H, Shah VP, Crison JR, A theoretical basis for a biopharmaceutic drug classification: the correlation of in vitro drug product dissolution and in vivo bioavailability. Pharm Res., 1995; 12(3): 413-420.

2. Atif M, Azeem M, Rehan SM, Potential problems and recommendations regarding substitution of generic antiepileptic drugs: a systematic review of literature. Springer Plus, 2016; 5:1-8.

3. Benet LZ, Concerns of Healthcare Practitioners and Patients, in AAPS/FIP/RA/SSFR International Regulatory Workshop on Bioequivalence and Dissolution, Bucharest, December 4-5, 2003.

4. Borchard G, Flühmann B, Mühlebach S, Nanoparticle iron medicinal products-Requirements for approval of intended copies of non-biological complex drugs (NBCD) and the importance of clinical comparative studies. Reg Tox Pharmacol., 2012; 64(2), 324-328.

5. BPCI Act. Biologics Price Competition and Innovation Act of 2009. Federal Register. 2010; H.R. 3590-686-702, www.fda.gov.

6. Broccatelli FL, Cruciani G, Oprea TI, Benet LZ, The Use of BDDCS in Predicting the Brain Disposition of Orally Administered Drugs. Advanced Drug Delivery Reviews, 2012; 64: 95-109.

7. Davit BM, Nwakama PE, Buehler GJ, Conner DP, Haidar SH, Patel DT, Yang Y, Yu LX, Woodcock $\mathrm{J}$, Comparing generic and innovator drugs: a review of 12 years of bioequivalence data from the United States Food and Drug Administration. Ann Pharmacother., 2009; 43(10): 1583-1597.

8. Statement on the biological medicines theme. Management în sănătate, 2017; XXI(1): 5-7 (available in Romanian).

9. EMEA, Guideline on Comparability of Medicinal Products Containing Biotechnology- derived Proteins as Drug Substance - Quality Issues. London, EMEA/ CHMP/BWP/3207/00/Rev 1. United Kingdom: The European Medicines Agency Evaluation of Medicines for Human Use; 2003.

10. Enache F, Mircioiu I, Corlan G, Sandulovici R, Mircioiu C, Estimation of therapeutic equivalence using bioequivalence statistical methods for Algopirin tablets versus Excedrin analgesic formulations. Farmacia, 2012; 60(2): 227-239.

11. FDA Guidance, Extended Release Oral Dosage Forms: Development, Evaluation and Application of an In vitro/In vivo Correlation, US Food and 


\author{
Drug Administration Center for Drug Evaluation \\ and Research, 1997.
}

12. FDA, Waiver of in vivo bioavailability and bioequivalence studies for immediate-release solid oral dosage forms based on a biopharmaceutics classification system, 2017.

13. Gherghiceanu F, Sandulovici R, Prasacu I, Anuta $\mathrm{V}$, Mircioiu C, Bioequivalence implies therapeutic equivalence. I. Biostatistical approach. Farmacia, 2016; 64 (6): 823-827.

14. Gherghiceanu F, Mircioiu C, Lupuleasa D, Mircioiu I, Iordache M, Toderescu C D, Sandulovici R, Bioequivalence implies therapeutic equivalence. II. Economic and social approach Studia Universitatis "Vasile Goldiş", Seria Ştiinţele Vieţii, 2017; 27(1): 55-61.

15. http://blogs.fda.gov.

16. Decision Nr. $155 / 30.03 .2017$ for the approval of the national health programmes 2017-2018, Romania Government. Monitorul Oficial, 2017; 222/31.03.2017 (available in Romanian).

17. ICH Q6B Guideline on Test Procedures and Acceptance Criteria for Biotechnological/Biological Products. Rockville, Maryland, USA: Center for Drug Evaluation and Research, Center for Biologics Evaluation and Research, the US Food and Drug Administration; 1999.

18. Interchangeability of Biosimilars - Position of Finnish Medicines Agency Fimea (Mayo 2015), www.fimea.fi.

19. List of Interchangeable Medicines 2018, www.hpra.ie.

20. Marchidanu D, Raducanu N, Miron DS, Comparative pharmacokinetics of rifampicin and 25-desacetyl rifampicin in healthy volunteers after single oral dose administration. Farmacia, 2013; 61(2): 398-410.

21. Mircioiu C, Perju A, Neagu A, Pharmacokinetics of progesterone in postmenopausal women: 1 . Pharmacokinetics following intravaginal administration. Eur J Drug Metab Pharmacokinetics, 1998; 23(3), 391-396.

22. Mircioiu I, Anuta V, Purcaru SO, Radulescu F, Miron D, Dumitrescu IB, Ibrahim N, Mircioiu C, In Vitro Dissolution of Poorly Soluble Drugs in the Presence of Surface Active Agents - in Vivo Pharmacokinetics Correlations. II. Nimesulide. Farmacia, 2013; 61(1): 88-102.

23. Mircioiu C, Voicu V, Miron D, Mircioiu I, Nonstandard correlations: In vitro in vivo correlations for immediate release products: Comparison of different bioequivalence experiments. Basic \& Clin Pharmacol \& Toxicol., 2005; 96(3): 259-261.

24. Mircioiu C, Mircioiu I, Voicu V, Miron D, Dissolution-bioequivalence non-correlations. Basic Clin Pharmacol Toxicol., 2005; 96: 262-264.

25. Mulcahy A, Jakub P. Hlávka, Spencer R. Case, Biosimilar Cost Savings in the United States Initial Experience and Future Potential, 2017, www.rand.org/.

26. Prasacu I, Mircioiu C, Sandulovici R, Enache F, Release of metoprolol from solid dosage forms. choice and validation of theoretical model, Farmacia, 2009; 57(1): 89-98.

27. Preda I, Mircioiu I, Mircioiu C, Research concerning the development of a biorelevant dissolution test for formulations containing norfloxacin. I. Modelling of in vitro release kinetics. Farmacia, 2012; 60(5): 675-687.

28. Sandulovici R, Vatasescu A, Enache F, Mircioiu C, Failure of statistical methods to prove bioequivalence of two meloxicam bioequivalent formulations. II. Nonparametric methods, Farmacia, 2011; 59(3): 367-380.

29. Schuirmann DJ, A comparison of the two one-sided tests procedure and the power approach for assessing the equivalence of average bioavailability. $J$ Pharmacokinet Biopharm, 1987; 15: 657-680.

30. Schall R, Luus HG, On population and individual bioequivalence. StatMed. 1993; 12: 1109-1124.

31. Shah Vinod P, Yacobi A, Radulescu, FS, A science based approach to topical drug classification system (TCS). Int J Pharmaceut., 2015; 491(1-2): 21-25.

32. Taerel AE, Rosenberg L, Nicolescu T, Ethics and equity in providing pharmaceutical assistance to the population. Revista Romana de Bioetica, 2010; 8(1): 150-154.

33. Tvrdonova M, Dedik L, Mircioiu C, Physiologically motivated time-delay model to account for mechanisms underlying enterohepatic circulation of piroxicam in human beings. Basic \& clinical pharmacology \& toxicology, 2009; 104(1): 35-42.

34. Vatasescu A, Enache F, Mircioiu C, Miron DS, Sandulovici R, Failure of statistical methods to prove bioequivalence of meloxicam drug products. I. Parametric methods, Farmacia, 2011; 59(2): 161-171.

35. Wagner JG, Nelson E, Kinetic Analysis of Blood Levels and Urinary Excretion in the Absorptive Phase after Single Doses of Drug. J Pharm Sci, 1964; 53: 1392-1403.

36. www.gabionline.net/Sponsored-Articles/ Legislations-on-biosimilar-interchangeability-inthe-US-and-EU-developments-far-from-visibility.

37. www.gabionline.net/Reports/Naming-andinterchangeability-for-biosimilars-in-Japan.

38. www.nasdaqomxnordic.com/.../firstnorth/fncorpora teactions/2016.

39. www.fda.gov/Drugs/GuidanceComplianceRegulato ryInformation/Guidances/default.htm January 2017.

40. www.fda.gov/Drugs/DevelopmentApprovalProcess /.../Biosimilars/ucm411418.htm.

41. www.law360.com/articles/507058, 2014, Laetitia Benard. France's Biosimilar Law May Set Trend Inside The EU, Expert Analysis.

42. www.pei.de/DE/arzneimittel/immunglobulinemonoklonale-antikoerper/monoklonale-.../positionpei-interchangebility-biosimilars-inhalt.html. Position des Paul-Ehrlich-Instituts zum Einsatz von Biosimilars (Diciembre 2015).

43. www.hpra.ie/docs/default-source/publicationsforms/guidance-documents/guide-to-biosimilarsfor-healthcare-professionals-and-patientsv1.pdf?sfvrsn=6. Guide to Biosimilars for Healthcare Professionals and Patients (December 2015).

44. https://accessiblemeds.org/resources/blog/2017generic-drug-access-and-savings-us-report. Association for Accessible Medicines, 2017 Generic Drug Access and Saving Report in the U.S. (2017). 